\title{
Diet intervention to improve cardiovascular risk factors among Iranian postmenopausal women
}

\author{
Parvin Abedi ${ }^{1 \S}$, Mary Huang Soo Lee ${ }^{2}$, Mirnalini Kandiah ${ }^{2}$, Zaitun Yassin², Davood Shojaeezade ${ }^{3}$, \\ Mostafa Hosseini ${ }^{4}$ and Reza Malihi ${ }^{5}$ \\ ${ }^{1}$ Department of Midwifery, Ahvaz Jondishapur University of Medical Science, $13^{\text {th }}$ East Kianpars Ave- Karkeh St- No 8, Ahvaz \\ 6155975381, Iran \\ ${ }^{2}$ Department of Nutrition and Dietetics, Universiti of Putra Malaysia, Selangor- 43300, Malaysia \\ ${ }^{3}$ Department of Health, Tehran University of Medical Science, Tehran, Iran \\ ${ }^{4}$ Department of Statistics, Tehran University of Medical Science, Tehran, Iran \\ ${ }^{5}$ Department of Nutrition, Ahvaz, Jondishapur University of Medical Science, Ahvaz, Iran
}

\begin{abstract}
Cardiovascular disease is a leading cause of death and disability and remains so in the future. The aim of this study was to detect the impact of a 6-month diet intervention on cardiovascular risk factors in postmenopausal Iranian women. It was a randomized controlled trial that carried out in the East Health Clinic in Ahvaz- Iran. This study started on June 2007 and was completed on May 2008. A total 64 healthy postmenopausal women recruited and randomly assigned to the intervention group (35) and control (29). Over the six months follow-up, the intervention group received five educational sessions (two face to face and three lecture discussion classes with slide demonstration) at the first month. These sessions were about menopause, cardiovascular disease and healthy diet. Every participant in the intervention group received one face to face education session at the $3^{\text {rd }}$ month, and also received a telephone call at the end of each month starting with the second month to remain on the diet. Pre-intervention and post-intervention anthropometric measurements, blood pressure, blood lipids and dietary intake were assessed. Data analyzed using the SPSS version 15. Descriptive (means and SD), univariate (Paired-t test, Chi-Square and Independent T-test) and multivariate (GLM Repeated Measure) statistics were used. Participants in the diet group had significantly lower weight $(-0.9 \mathrm{~kg})$, body mass index $\left(-0.4 \mathrm{~kg} / \mathrm{m}^{2}\right)$, and fasting blood sugar $(-4.5 \mathrm{mg} / \mathrm{dl})$. The diet group significantly increased their daily intake of fiber $(+2.3 \mathrm{~g}, P=0.05)$, decreased their intake of sodium $(-28 \mathrm{mg}, P=$ $0.04)$, and consumption of fruit and vegetable $\geq 5$ serving a day $(80 \%, P=0.03)$ compared to the control group. Post menopausal women are at a greater risk for cardiovascular disease. Healthy diet using educational intervention can be an effective means of reducing cardiovascular risk in postmenopausal women.
\end{abstract}

Key Words: Postmenopausal women, cardiovascular disease, diet intervention

\section{Introduction}

Globally, cardiovascular disease (CVD) is the number one cause of death and is projected to remain so in the future. An estimated 17.5 million people died from CVD in 2005 alone, representing $30 \%$ of all global deaths. Around $80 \%$ of these deaths occurred in low and middle-income countries [1]. In countries of the Eastern Mediterranean Region (including Iran), increasing economic wealth along with rapid population growth have led to an increasing mortality rate from CVD [2]. In the Iranian Ministry of Health and Medical Education (MOH \& ME) Death Registration System, data on causes of death are collected from various sources and have been assessed. According to this latest data (2004), the main cause of death in Iran was CVD which accounted for almost half (40\%) of total deaths [3].
Menopause is a risk factor for CVD because estrogen withdrawal has a detrimental effect on cardiovascular function and metabolism [4]. Men and women are similar in some coronary heart disease (CHD) risk factors such as age, dyslipidemia, hypertension, smoking, diabetes, obesity and physical inactivity. Besides that, women have additional risk factors, such as the use of contraceptives and the reduction of ovarian function after menopause [5]. Menopause, obesity, and sedentary lifestyle are independent risk factors for cardiovascular disease (CVD) [6,7]. Several research investigations have suggested that as women enter menopause, there is a marked increase in the prevalence of atherosclerosis and clinical CVD, including a greater likelihood of myocardial infarction (MI) and all-causes of mortality [8-10]. In the Healthy Women Study in which enrolled 541 middle-aged women when they were

\footnotetext{
${ }^{\S}$ Corresponding Author: Parvin Abedi, Tel. 009891-6313-2793, Email. parvinabedi@yahoo.com

Received: July 11, 2010, Revised: December 12, 2010, Accepted: December 12, 2010

(c)2010 The Korean Nutrition Society and the Korean Society of Community Nutrition

This is an Open Access article distributed under the terms of the Creative Commons Attribution Non-Commercial License (http://creativecommons.org/licenses/by-nc/3.0/)

which permits unrestricted non-commercial use, distribution, and reproduction in any medium, provided the original work is properly cited.
} 
premenopausal and followed them through menopause, reported that weight gain in transition from pre-menopause to menopause was significantly associated with increases in blood pressure, total cholesterol, low-density lipoprotein (LDL), triglycerides and fasting insulin [10]. Increasing weight in postmenopausal women was related to increases in CHD risk factors (i.e., a significant decrease in high-density lipoprotein [HDL] and an increase in LDL). Weight gain during and after menopause can contribute more to CVD than weight gain prior to menopause and that weight loss and increased physical activity could mitigate some of the CVD risk factors (i.e., high cholesterol, insulin resistance). Not surprisingly, a panel of experts convened through the National Cholesterol Education Program (NCEP) concluded that therapeutic lifestyle change, emphasizing increased physical activity, reduced intake of fat and cholesterol, and moderate weight loss, is "the foundation of clinical primary prevention" of CVD [11]. These conclusions regarding lifestyle change can be significant in the light of recent research suggesting that lifestyle changes can be considered as a primary prevention and treatment of CVD in postmenopausal women.

Healthy lifestyle is an important strategy for the whole community, and it revolves around a balanced diet, avoiding saturated fats, taking regular exercise, reducing weight and not smoking.

The present study examined the effect of an educational program on healthy diet interventions at reducing cardiovascular risk defined in this study as weight loss, body composition, diet, blood pressure (BP) and blood lipids.

\section{Materials and Methods}

\section{Screening and recruitment}

Participants were 76 sedentary postmenopausal women, who were randomly assigned to receive healthy diet educational intervention or no intervention (control group). Screening for participants took place at the number 1 Eastern Health Clinic of the Ahvaz Medical University of Jondishapur, Iran. This study started on June 2007 and was completed on May 2008 and every woman followed for six months. The ethical committee of Universiti of Putra Malaysia and Medical University of Jondishapur in Ahvaz -Iran approved the study. Women were included in the study if they had at least primary education, postmenopausal (no menstruation for at least 12 months), CVD free (not on a medication basis on self report history). An informed consent was obtained from all participants prior to study.

At baseline, participants completed assessments of anthropometry, blood lipids, fasting blood glucose, dietary intake using the food frequency questionnaire (48 items) and 24 hour recall (two week days and one weekend). All assessments were again obtained at the conclusion of the 6-month intervention. For analyzing data based on 24 hour dietary recall, the Iranian food composition table reference that has been designed by the Nutritional Society of Iran and contains 700 food items consumed by Iranian people was used.

\section{Development of the questionnaire}

The questionnaire consisted of five sections. The first section was for screening purposes, the second part was for collecting data on personal characteristics. Section 3 contained 24 hour recall for three days (two week days and one weekend) and food frequency questionnaire. Section 4 was used for recording data of physical and anthropometric measurements including the blood pressure. Section 5 was used for recording data from biochemical tests. The biochemical tests included lipid profiles (LDL, HDL, very low density lipoprotein, total cholesterol, Triglyceride), $\mathrm{C}$ - reactive protein (CRP), and fasting blood sugar (FBS).

\section{Intervention}

Two educational booklets, one was on menopause and CVD, the second one was on diet were prepared according to the updated American guideline for prevention of CVD in sedentary postmenopausal women. Participants in the diet group received these educational booklets. All participants in the intervention group trained in two face- to- face education sessions (at the first time and the $3^{\text {rd }}$ month), three lecture and group discussion sessions (about healthy diet) with slide demonstration weekly in the first month. Every participant received five telephones reminding to remain on healthy diet at the end of each month for five months.

In the diet group women persuaded to consume at least five servings fruits and vegetables, whole grain foods, high fiber foods, fish (two times per week), limit intake of saturated fat to less than $10 \%$ of energy, and if possible to less than $7 \%$, cholesterol to less than $300 \mathrm{mg} /$ day, and salt intake to less than $5 \mathrm{~g}$ /day (approximately one teaspoon). They educated to keep the consumption of Trans-fatty acids as low as possible (e.g. less than $1 \%$ of energy) $[12,13]$.

\section{Measurements}

The height and body weight of each participant were measured to the nearest $0.5 \mathrm{~cm}$ and $0.1 \mathrm{~kg}$ respectively, while barefooted and in light clothing using SECA digital bathroom scale and SECA tape height measure. Waist circumference was measured at the midway level between the costal margins and the iliac crests in the narrowest site. Hip circumference was measured at the level of the greater trochanters. Waist and hip circumferences were measured by using a measuring tape.

Blood pressure were taken with an Omron automatic blood pressure with digital monitor (Omron company, Japan) using an 
appropriate size cuff while the participant remains seated quietly and after a ten minutes rest.

Blood lipids and blood glucose were done using $5 \mathrm{ml}$ venous fasting blood of participants. For all biochemical tests, one reference laboratory in Ahvaz (Tohidy) was used. Blood was drawn by a trained laboratory technician. The researcher supervised stages of blood testing by going at least once a week to the laboratory. For detecting of blood lipids and blood glucose the standard methods were used $[13,14]$.

The dietary intake was assessed using the food frequency questionnaire (48 items) and 24 hour recall over three days (two weekdays and one weekend). For analyzing data based on the 24 hour dietary recall, the Iranian food composition table that had been designed by the Nutritional Society of Iran and containing 700 food items consumed by Iranian people was used. Mixed foods were broken down into their ingredients [15].

\section{Statistical analysis}

Data analysis was conducted by using the Statistical Package for Social Science (SPSS 15). Descriptive analysis was carried out to obtain mean and standard deviation for all continuous data. The data gathered from the 24 hour recall questionnaire, analyzed using the Iranian food processing software which has the ability to calculate almost 700 types of nutrients and was also able to produce the graphs to compare participant's consumption with RDAs for essential nutrients [15].

For between- group comparisons, Independent T-test was used to determine differences in mean among the intervention and control groups. The Chi-Square test was used to determine the differences in distribution across different categories among the two groups for categorical data. For within group comparison over the $6^{\text {th }}$ month, the Paired- $t$ test was applied. In order to assess changes over the six months intervention between groups, General Linear Model (GLM) repeated measures test adjusted for SE covariance was applied for continuous and categorical data. The level of significance was set at $(P<0.05)$ for all statistical analyses.

\section{Results}

After six months 12 subjects dropped out (three in the diet group and nine in the control group) (did not attend in the classes, or did not provide any reason). A total of 64 women completed six months trial, 35 in the diet and 29 in the control group. There were no statistically significant differences between the diet and control groups on the demographic, anthropometric, blood lipid and glucose and dietary intake at baseline (Table 1).

Table 1. Demographic and baseline characteristics of participants

\begin{tabular}{|c|c|c|}
\hline \multirow[t]{2}{*}{ Characteristics } & $\begin{array}{c}\text { Diet } \\
(n=35)\end{array}$ & $\begin{array}{l}\text { Control } \\
(n=29) \\
\end{array}$ \\
\hline & Mean (SD) & Mean (SD) \\
\hline \multicolumn{3}{|l|}{ Demographic } \\
\hline Age & $51.4(4.9)$ & $51.6(5.7)$ \\
\hline Age of menopause & $47.5(3.9)$ & $45.5(10.1)$ \\
\hline No of children & $4.5(1.4)$ & $4.6(1.7)$ \\
\hline College degree (n (\%)) & $1(2.9)$ & $2(6.9)$ \\
\hline \multicolumn{3}{|l|}{ Body composition } \\
\hline Weight (kg) & $70.3(12)$ & $71.2(14.4)$ \\
\hline Body mass index $\left(\mathrm{kg} / \mathrm{m}^{2}\right)$ & $30.1(6.2)$ & $30.8(30.8)$ \\
\hline Waist circumference $(\mathrm{cm})$ & $88.1(10)$ & $89.7(10.4)$ \\
\hline Waist hip ratio & $0.81(0.06)$ & $0.82(0.05)$ \\
\hline \multicolumn{3}{|l|}{ Biochemical } \\
\hline Total cholesterol (mg/dl) & $220(26)$ & $221(39)$ \\
\hline Triglyceride (mg/dl) & $148.1(69)$ & $156.5(86)$ \\
\hline Low density lipoprotein (mg/dl) & $140(27)$ & $139.7(34)$ \\
\hline High density lipoprotein (mg/dl) & $47.6(7)$ & $46.1(7)$ \\
\hline Fasting blood glucose (mg/dl) & $96.8(30)$ & $98.8(17)$ \\
\hline \multicolumn{3}{|l|}{ Blood pressure } \\
\hline Systolic (mmHg) & $118.6(16)$ & $116.4(10)$ \\
\hline Diastolic (mmHg) & $80.8(11.2)$ & $76.6(10.5)$ \\
\hline \multicolumn{3}{|l|}{ Diet } \\
\hline Energy (kcal) & $2,077(781)$ & $2,000(561)$ \\
\hline \%Daily calorie from carbohydrate & $48(11)$ & $50(9)$ \\
\hline \%Daily calorie from protein & $11(3)$ & $12(3)$ \\
\hline$\%$ Daily calorie from total fat & $32(7)$ & $33(6)$ \\
\hline$\%$ Daily calorie from saturated fat & $5(2)$ & $4(2)$ \\
\hline
\end{tabular}

Table 2. Physical and clinical characteristics of participants in the intervention and control groups before and after intervention

\begin{tabular}{|c|c|c|c|c|c|c|c|}
\hline \multirow[t]{2}{*}{ Characteristics } & \multicolumn{3}{|c|}{$\begin{array}{c}\text { Diet } \\
(n=35)\end{array}$} & \multicolumn{3}{|c|}{$\begin{array}{l}\text { Control } \\
(n=29)\end{array}$} & \multirow{2}{*}{$\begin{array}{c}\text { Between } \\
\text { groups }\end{array}$} \\
\hline & Before & After & Mean changes & Before & After & Mean changes & \\
\hline Weight (kg) & 70.3 & 69.4 & $-0.9^{\dagger}$ & 71.2 & 71.4 & 0.2 & NS \\
\hline Body Mass Index $\left(\mathrm{kg} / \mathrm{m}^{2}\right)$ & 30.1 & 29.7 & $-0.4^{\dagger}$ & 30.8 & 30.9 & -0.1 & NS \\
\hline Waist to hip ratio & 0.81 & 0.83 & 0.02 & 0.82 & 0.83 & 0.01 & NS \\
\hline Systolic blood pressure $(\mathrm{mmHg})$ & 118.6 & 121.1 & 2.5 & 116.4 & 120 & 3.6 & NS \\
\hline Diastolic blood pressure $(\mathrm{mmHg})$ & 80.8 & 79.8 & -1 & 76.6 & 77.3 & 0.7 & NS \\
\hline Total cholesterol (mg/dl) & 220 & 208 & $-12^{\dagger}$ & 221 & 209 & $-12^{\dagger}$ & NS \\
\hline Triglyceride (mg/dl) & 148.1 & 129.2 & $-18.9^{\dagger}$ & 156.5 & 142 & -10.2 & NS \\
\hline Low density lipoprotein (mg/dl) & 140 & 134 & -6 & 139.7 & 127 & -7 & NS \\
\hline High density lipoprotein (mg/dl) & 47.6 & 48 & 0.40 & 46.1 & 46 & -0.1 & NS \\
\hline Fasting blood sugar (mg/dl) & 96.8 & 92.3 & $-4.5^{\dagger}$ & 98.8 & 93.8 & -3.5 & NS \\
\hline
\end{tabular}

${ }^{+}$Significant difference before and after intervention within group 
Table 3. Dietary Intake of participants in the intervention and control groups before and after intervention

\begin{tabular}{|c|c|c|c|c|c|c|c|}
\hline \multirow[t]{2}{*}{ Characteristics } & \multicolumn{3}{|c|}{$\begin{array}{c}\text { Diet } \\
(\mathrm{n}=35)\end{array}$} & \multicolumn{3}{|c|}{$\begin{array}{l}\text { Control } \\
(n=29)\end{array}$} & \multirow{2}{*}{$\begin{array}{c}\text { Between } \\
\text { groups }\end{array}$} \\
\hline & Before & After & Mean changes & Before & After & Mean changes & \\
\hline Energy & 2003 & 2118 & 115 & 1987 & 2119 & 132 & NS \\
\hline \%Daily calorie from carbohydrate & 48 & 43 & -5 & 50 & 49 & -1 & NS \\
\hline$\%$ Daily calorie from protein & 11 & 12 & 1 & 12 & 12 & 0 & NS \\
\hline$\%$ Daily calorie from total fat & 32 & 32 & 0 & 33 & 34 & 1 & NS \\
\hline$\%$ Daily calorie from saturated fat & 5 & 5 & 0 & 4 & 5 & 1 & NS \\
\hline Dietary cholesterol (g) & 83.7 & 88.6 & 5.1 & 100 & 115 & 15 & NS \\
\hline Dietary fiber intake $(\mathrm{g})$ & 2.8 & 5.1 & $2.3^{\dagger}$ & 2.4 & 2.8 & 0.4 & $P=0.05^{*}$ \\
\hline Sodium (mg) & 1041 & 1012 & $-28^{+}$ & 925 & 1403 & 477 & $P=0.04^{*}$ \\
\hline Fruit and vegetable $\geq 5$ serving a day ( $n(\%)$ ) & $9(25.7)$ & $28(80)$ & $+19^{+}$ & $7(24.1)$ & $14(48.3)$ & +7 & \multirow{2}{*}{$P=0.03^{*}$} \\
\hline Fruit and vegetable $<5$ serving a day ( $\mathrm{n}(\%)$ ) & $26(74.3)$ & $7(20)$ & -19 & $22(75.9)$ & $15(51.7)$ & -7 & \\
\hline Salt $<5$ g day $(\mathrm{n}(\%))$ & $15(42.8)$ & $20(57.1)$ & +5 & $14(48.2)$ & $15(51.7)$ & +1 & \multirow{2}{*}{ NS } \\
\hline Salt $>5 \mathrm{~g}$ day $(\mathrm{n}(\%))$ & $20(57.1)$ & $15(42.8)$ & -5 & $16(55.1)$ & $13(44.8)$ & -3 & \\
\hline
\end{tabular}

* $P<0.05$ ** $P<0.01$

+Significant difference with the control group

\section{Changes in anthropometric}

There were significant differences in the weight and BMI $(P$ $<0.05)$ of participants in the diet group before and after intervention (Table 2). There was no significant difference in the anthropometric between diet and control groups after treatment.

\section{Changes in BP, blood lipids and glucose}

There was no significant difference within groups and between groups in the blood pressure.

There was significant difference in the diet group before and after intervention in the TG $(0.05)$ and FBS $(P<0.05)$. There was no significant difference between diet and control groups in blood lipids and blood glucose.

\section{Changes in dietary intake}

There was significant difference before and after intervention from dietary fiber intake in the diet group $(P<0.01)$ (Table 3$)$. The percentages of energy from carbohydrate reduced in the diet group more than the control group (mean difference -5 and -1 respectively), however it was not significant.

The percentages of daily calorie from protein, total fat and saturated fat had negligible changes or remained unchanged among intervention and control groups. Dietary cholesterol increased in two groups with more increase in the control group (from $100 \mathrm{~g}$ to $115 \mathrm{~g}$ ). The sodium intake decreased in the diet group ( from $1,041 \mathrm{mg}$ to $1,012 \mathrm{mg}$ ) but increased in the control group (from $925 \mathrm{mg}$ to $1,403 \mathrm{mg})(P=0.04)$. The GLM repeated measure showed that the diet group had significant difference with the control group in dietary fiber intake and sodium intake $(P=0.05)$.

The number of participants who could increase their fruit and vegetables consumption in the diet group was significantly more than that in the control group (80\% compared to $48.3 \%, P=$ $0.03)$. The reduction of salt consumption in two study groups almost was the same.

\section{Discussion}

The primary aim of this research was to determine whether a 6-month educational intervention on diet would significantly improve CVD risk factors in postmenopausal Iranian women. The women in the intervention group exhibited some significant improvement in weight loss, BMI, total cholesterol, TG, LDL, FBS, daily intake of dietary fiber and sodium intake.

Participants in the diet group significantly lowered their weight, BMI, total cholesterol $(-12 \mathrm{mg} / \mathrm{dl})$, TG $(-18.9 \mathrm{mg} / \mathrm{dl})$ and FBS (-4.5). Considerable weight loss and BMI reduction demonstrated in other investigation $(9.7 \mathrm{~kg}$ and $6.2 \mathrm{~kg}$ over 26 weeks of treatment) $[16,17]$. These disparate findings are due to than in our study, women in the diet group did not encourage to do physical activity and they trained to decrease their dietary fat to less than $30 \%$. However greater changes happened with dietary restriction of energy from fat to less than $25 \%$ and even $15 \%$ [18]. The blood lipid changes in the present study are similar to other investigations [17]. The HDL increase in the diet group was negligible $(0.40 \mathrm{mg} / \mathrm{dl})$ confirming that diet restriction without exercise cannot increase the HDL level [19].

In the present study, the percentages of energy from total fat and saturated fat in the diet group did not changed; however they could increase their dietary fiber intake. Fiber can decrease blood cholesterol levels. Fiber works by attaching itself to the cholesterol so that it can be eliminated from the body. This process prevents cholesterol from recirculation and being reabsorbed into the bloodstream and can decrease the blood cholesterol [20]. In a cross-sectional study, the researchers found 
that highest total dietary fiber intake were associated with a significantly $(P<0.05)$ lower risk of overweight and elevated WHR, blood pressure, blood cholesterol, TG and homocysteine [21].

The educational intervention in the present study has been successful in reducing some dietary risk factors of CVD including increasing the consumption of fruit, vegetables and fiber and decreasing consumption of salt. A study in Iran-Tehran with 840 adult participants showed that increasing in consumption of fruit and vegetable were inversely associated with CVD risk factors e.g. LDL and total cholesterol [22]. The findings of the present study is similar with the study in Tehran, as LDL and FBS of participants in the diet group reduced significantly. Participants in study did not reduce the percentages of energy from fat, or dietary cholesterol. Other investigation with combining of diet and exercise education could reduce the daily calorie from fat and saturated fat [17]. These disparate findings are likely secondary to the participants in other research underwent the exercise and dietary intake change at the same time, but in the present study participants in the intervention group got healthy diet educational intervention solely. Furthermore the diet which recommended to participants in this study was intake of fat $<30 \%$ of total energy. Other investigations could reduce the percentages of energy from total fat with intake of fat $<25 \%$ and even $<15 \%$.

Although the findings in this investigation suggest an association between diet intervention and reduced cardiovascular risks, these conclusions should be viewed tentatively, and replication is warranted for several reasons. The participants in the study were not well educated, and only $2.9 \%$ of diet and 6.95 of the control group had college degree. Secondly the participants in the diet group did not train according to their educational level. Thirdly all dietary intakes gathered through interview and self-report. Therefore, the self-reported levels and changes in dietary intake should be viewed with caution. Research suggests that when 3-4-day food records are evaluated against doubly labeled water, under-reporting can range from $10 \%$ to $32 \%$ [21].

The findings in this investigation are encouraging for a number of reasons. Obesity peaks after menopause, and being postmenopausal, obese, and sedentary are independent risk factors for CVD [6-8]. The main strength of this study is that this was a randomized study and intensive intervention trial. In addition this was the first time in Iran that postmenopausal women were chosen randomly for changing lifestyle with emphasizing on healthy diet and followed up for six months. The lifestyle change intervention in this investigation, through its encouragement of gradual weight loss, and a progressive decrease in energy and fat intake through self-selected, permanent, lifestyle changes, may be a cost-effective treatment for reducing CVD risk in postmenopausal women. Lifestyle change intervention with emphasizing on healthy diet can be an effective means of reducing cardiovascular risk in obese postmenopausal women.

\section{Acknowledgement}

Thanks to the Universiti Putra Malaysia and its lecturers for the supervision, constructive suggestion and immense amount of guidance throughout this Ph.D thesis. Appreciation is also extended to the Medical University of Jondishapor in Ahvaz-Iran for their cooperation during the data collection.

\section{References}

1. Mendis S, Lindholm LH, Mancia G, Whitworth J, Alderman M, Lim S, Heagerty T. World Health Organization (WHO) and International Society of Hypertension (ISH) risk prediction charts: assessment of cardiovascular risk for prevention and control of cardiovascular disease in low and middle-income countries. J Hypertens 2007;25:1578-82.

2. Fakhrzadeh H, Bandarian F, Adibi H, Samavati H, Malekafzali $\mathrm{H}$, Hodjazadeh E, Larijani B. Coronary heart disease and associated risk factors in Qazvin: a population-based study. East Mediterr Health J 2008;14:33-41.

3. Khosravi A, Taylor R, Naghavi M, Lopez AD. Mortality in the Islamic Republic of Iran, 1964-2004. Bull World Health Organ 2007;85:607-14.

4. Rosano GM, Vitale C, Marazzi G, Volterrani M. Menopause and cardiovascular disease: the evidence. Climacteric 2007;10:19-24.

5. Bush TL, Fried LP, Barrett-Connor E. Cholesterol, lipoproteins, and coronary heart disease in women. Clin Chem 1988;34: B60-70.

6. Manson JE, Hu FB, Rich-Edwards JW, Colditz GA, Stampfer MJ, Willett WC, Speizer FE, Hennekens CH. A prospective study of walking as compared with vigorous exercise in the prevention of coronary heart disease in women. N Engl J Med 1999; 341:650-8.

7. Hjortland M, McNamara PM, Kannel W. Some atherogenic concomitants of menopause: The Framingham Study. Am J Epidemiol 1976;103:304-11.

8. Matthews KA, Meilahn E, Kuller LH, Kelsey SF, Caggiula AW, Wing RR. Menopause and risk factors for coronary heart disease. N Engl J Med 1989;321:641-6.

9. Wing RR, Marcus MD, Epstein LH, Jawad A. A "family-based" approach to the treatment of obese type II diabetic patients. J Consult Clin Psychol 1991;59:156-62.

10. Haddock BL, Marshak HP, Mason JJ, Blix G. The effect of hormone replacement therapy and exercise on cardiovascular disease risk factors in postmenopausal women. Sports Med 2000;29:39-49.

11. Mosca L, Banka CL, Benjamin EJ, Berra K, Bushnell C, Dolor RJ, Ganiats TG, Gomes AS, Gornik HL, et al. Evidence-based guidelines for cardiovascular disease prevention in women: 2007 update. Circulation 2007;115:1481-501.

12. Ministry of Health and Medical Education [Internet]. Iran: 2007 Available from: http://www.behdasht.gov.ir.

13. Expert Panel on Detection, Evaluation, and Treatment of High Blood Cholesterol in Adults. Executive summary of the third report of the national cholesterol education program (NCEP) expert panel on detection, evaluation, and treatment of high blood cholesterol in adults (Adult Treatment Panel III). JAMA 2001; 285:2486-97. 
14. Thomas L. Clinical laboratory diagnostics. $1^{\text {st }}$ Ed. Frankfurt: THBooks Verlagsgesellschaft; 1998. p.131-7.

15. Dorosty AR, Tabatabaee M. The food composition table. The Iranian Nutrition World Journal 2007;16:15-20.

16. Wing R, Polley B. Obesity. In: Baum A, Revenson T, Singer J. Handbook of health psychology. Mahwah, NJ: Lawrence Erlbaum: 2001. p.263.

17. Carels RA, Darby LA, Cacciapaglia HM, Douglass OM. Reducing cardiovascular risk factors in postmenopausal women through a lifestyle change intervention. J Womens Health (Larchmt) 2004; 13:412-26.

18. Kasim-Karakas SE, Almario RU, Mueller WM, Peerson J. Changes in plasma lipoproteins during low-fat, high-carbohydrate diets: effects of energy intake. Am J Clin Nutr 2000;71:1439-47.
19. McEligot AJ, Gilpin EA, Rock CL, Newman V, Hollenbach KA, Thomson CA, Pierce JP. High dietary fiber consumption is not associated with gastrointestinal discomfort in a diet intervention trial. J Am Diet Assoc 2002;102:549-51.

20. Lairon D, Arnault N, Bertrais S, Planells R, Clero E, Hercberg $\mathrm{S}$, Boutron-Ruault MC. Dietary fiber intake and risk factors for cardiovascular disease in French adults. Am J Clin Nutr 2005; 82:1185-94.

21. Trabulsi J, Schoeller DA. Evaluation of dietary assessment instruments against doubly labeled water, a biomarker of habitual energy intake. Am J Physiol Endocrinol Metab 2001;281:E891-9.

22. Mirmiran P, Noori N, Zavareh MB, Azizi F. Fruit and vegetable consumption and risk factors for cardiovascular disease. Metabolism 2009;58:460-8 